\title{
O paciente com câncer, cognições e emoções oriundas da dor: uma revisão literária a partir de uma perspectiva psicológica
}

\author{
The patient with cancer, cognitions and emotions from pain: a literary review from a psychological \\ perspective
}

\author{
Milena Freitas Da Silva ${ }^{1^{*}} \bullet$, Julianne Milenna Padilha Rolim ${ }^{2} \bullet$ \\ ${ }^{1}$ Discente do curso de Psicologia, Autarquia de Ensino Superior de Arcoverde, Arcoverde, Pernambuco, Brasil. ${ }^{2}$ Docente, Psicóloga, \\ Mestra, Autarquia de Ensino Superior de Arcoverde, Arcoverde, Pernambuco, Brasil. *Autor para correspondência. E-mail: \\ milafreitas0601@gmail.com
}

\begin{abstract}
Resumo: Introdução: A psicologia oncológica tem como principal característica estudar as ações emocionais a partir da oncologia, visando um atendimento não só ao paciente como também ao seu núcleo familiar, considerando o despertar das emoções do paciente e auxiliando essa área de atuação. Revisão e discussão: O presente estudo corrobora na compreensão de pesquisas nacionais que abordam o sofrimento psíquico diante do câncer bem como as emoções desenvolvidas diante do tratamento definindo as características da dor nesse contexto e observando como o paciente define as etapas por ele vivenciadas compreendendo a dor enquanto aspecto emocional e não somente físico. Considerações finais: A partir desses aspectos apresentamos as incidências e prevalências do câncer caracterizando as questões relativas à dor e seus impactos com relação a questões neurais e emocionais, contribuindo assim para o desenvolvimento de práticas assertivas no que diz respeito aos pacientes oncológicos, ampliando a visão para o sujeito e suas demandas.
\end{abstract}

Palavras-chave: oncologia, psicologia, câncer.

\begin{abstract}
Introduction: Oncology psychology has as its main characteristic the study of emotional actions based on oncology, aiming at providing care not only to the patient but also to their family nucleus, considering the awakening of the patient's emotions and helping this area of expertise. Review and discussion: This study corroborates the understanding of national research that address the psychological suffering of cancer as well as the emotions developed in the face of treatment, defining the characteristics of pain in this context and observing how the patient defines the stages experienced by him, understanding pain as an aspect emotional and not just physical. Final considerations: Based on these aspects, we present the incidence and prevalence of cancer, characterizing issues related to pain and its impacts in relation to neural and emotional issues, thus contributing to the development of assertive practices with regard to cancer patients, broadening the vision for the subject and its demands.
\end{abstract}

Keywords: oncology, psychology, cancer.

\section{Introdução}

A Psico-oncologia consiste na interface entre a psicologia e a oncologia e traz como possibilidade a reestruturação da pessoa adoecida e reinserção do sujeito no mundo. Essa proposta vai de encontro com os princípios da Organização Mundial de Saúde (OMS) que define saúde não apenas como ausência de doença, mas como a situação de perfeito bem-estar físico, mental e social e não somente ausência de afecções e enfermidade. O adoecimento pelo câncer não é simplesmente um fato físico, mas um problema que diz respeito à pessoa como um todo, incluindo não apenas o corpo, mas também as emoções e a mente (Gimenes, 2010).

Os mitos em torno da doença e a subjetividade da pessoa adoecida, influenciam na maneira de elaborar as etapas do tratamento. A família também sofre em função das dúvidas e inseguranças da notícia sobre o câncer. Tanto os valores, quanto a história de vida, conhecimentos prévios, podem interferir na forma de lidar com a doença e sua aceitação ou negação (Venâncio, 2004).

Ao se deparar com o diagnóstico oncológico e o tratamento, o paciente e sua família vivenciam situações ligadas a angústia, ansiedade, medo e fantasias frente aos paradigmas do câncer, podendo influenciar a autoimagem, a mudança na rotina diária, dinâmica familiar e de trabalho, além de aspectos relacionados à 
sexualidade. Tais questões, podem provocar depressão, incertezas quanto ao futuro, transtornos gerais, dificuldade no relacionamento familiar e interpessoal (Carvalho, 2000).

O sofrimento emocional associado à doença, se ignorado, pode acarretar redução significativa na qualidade de vida do paciente e de seus familiares a afetar de forma negativa a adesão ao tratamento e reabilitação. $O$ papel do psicólogo será oferecer uma escuta clínica de forma ética e com excelência, buscando assegurar uma assistência integral e humanizada, com intuito de alcançar uma melhora na condição psíquica, minimizando os impactos sofridos durante o adoecimento (Amorim, 2009).

Mesmo com a existência de indicadores da expansão da atuação profissional em psico- oncologia no Brasil, um levantamento de dados efetuado junto aos trabalhos apresentados e temas discutidos durante os referidos congressos de psico-oncologia apontou os seguintes aspectos gerais: (a) a existência de um perfil profissional ainda um pouco assistencialista; e (b) uma maior quantidade de relatos de experiência profissional, em detrimento de estudos de investigação científica com rigor metodológico. O levantamento considerou a afiliação institucional e regional dos trabalhos, os temas em psico-oncologia que mais interessavam aos psicólogos, o tipo de trabalho desenvolvido e a variabilidade metodológica utilizada (Amorim, 2009).

O Instituto Nacional de Câncer/INCA, órgão de referência nacional no tratamento dessa patologia, apenas em 1979 contratou o primeiro psicólogo. Em 1985 o Setor de Psicologia passa a ser um Setor independente, com um corpo formado por seis profissionais. Em 2003 esta instituição criou o primeiro curso de especialização em Psicologia Oncológica, formando dez profissionais (Teixeira \& Pires, 2010).

A Psico-Oncologia é uma especialidade da Psicologia é uma subespecialidade da Oncologia que procura compreender as dimensões psicológicas presentes no diagnóstico oncológico, tais como o impacto do câncer no funcionamento emocional do paciente, de sua família e dos profissionais de saúde envolvidos em seu tratamento. A Psico-Oncologia representa a área de interface entre a Psicologia e a Oncologia. Antes de fazer as considerações necessárias acerca da Psico-Oncologia, faz-se necessária a definição de alguns conceitos básicos (Teixeira \& Pires, 2010).

Segundo o próprio INCA (2015) a Oncologia é a ciência e especialidade da medicina que estuda o câncer e como ele se forma, instala-se e progride, bem como as modalidades possíveis de tratamento, câncer ou enfermidades oncológicas são denominações utilizadas para descrever um grupo de doenças que se caracterizam pela anormalidade das células e sua divisão excessiva

A literatura especializada mostra que pacientes submetidos ao acompanhamento psicológico durante o tratamento do câncer obtêm ganhos significativos, tais como: melhora do estado geral de saúde, melhora da qualidade de vida, melhor tolerância aos efeitos adversos da terapêutica oncológica (quimioterapia/radioterapia e cirurgia) e melhor comunicação entre paciente, família e equipe. Dessa forma, percebe-se que as intervenções psicológicas podem ter consequências positivas tanto no aspecto emocional (depressão e ansiedade) quanto nos sintomas físicos (náuseas, vômitos e fadiga) (Gimenes, 2007).

Segundo Venâncio, 2004 Pesquisas mostram que as intervenções psicossociais influenciam positivamente o ajustamento emocional e funcional da paciente e aliviam os sintomas adversos decorrentes do câncer e do seu tratamento. Outra consequência de um bom trabalho psicoterápico é a participação mais ativa e positiva do paciente durante o tratamento, resultando numa melhor adesão, evitando assim, o abandono do mesmo. Estudos evidenciam que quando a paciente se encontra mais participativa durante o tratamento, há menor probabilidade do surgimento de intercorrências clínicas e psicológicas no mesmo.

Além desses resultados que o psicólogo busca em sua atuação, poderão ocorrer efeitos adicionais como o aumento do tempo de sobrevida da paciente. Gimenez (2007), propõe que a longevidade do paciente com câncer está relacionada com a capacidade de ajustamento do indivíduo à doença. Esta mesma autora enfatiza outros fatores que influenciam na sobrevida da paciente, tais como: expressão dos sentimentos, vontade de viver, reação ativa em relação ao tratamento e bom suporte social e afetivo. Fatores estes incentivados no trabalho psicoterápico (Miyazaki et al., 2001).

A confirmação do diagnóstico oncológico e a realização de procedimentos invasivos durante o tratamento, pode desencadear um desequilíbrio emocional tanto no paciente quanto em sua família. Ocorre uma mudança significativa na vida das pessoas após o diagnóstico de câncer, e tudo isso pode ser concebido como algo ameaçador à integridade física e mental desses indivíduos. O câncer é uma enfermidade ainda repleta de estigmas, associada à morte, e apesar de todo o conhecimento e informações acerca dessa enfermidade, $o$ diagnóstico do câncer tem usualmente um efeito devastador (Venâncio, 2004).

Em maior ou menor número, em diferentes momentos do processo da enfermidade, o paciente apresenta algum desconforto frente à essa nova realidade, independentemente de ter uma rede de apoio (família, amigos, associações, igreja) fortalecida ou uma crença religiosa e o psicólogo apesar da linha teórica que escolher (psicanálise, gestáltica, cognitiva comportamental, dentre outras), juntamente com a equipe 
competente, precisam prontamente atender as demandas desses pacientes a fim de obter melhores resultados durante o tratamento. Ou seja, o ponto de união desta área é o paciente de câncer.

Suas dificuldades, necessidades, problemas precisam ser atendidos, seja facilitando um melhor enfrentamento da doença e permitindo uma convivência melhor com ela, seja melhorando o estado psicológico e este levando a um melhor estado geral orgânico, auxiliando na recuperação e na cura, se possível (Miyazaki et al., 2001).

Ainda de acordo com o autor anterior na atuação do psicólogo juntamente com a equipe de saúde, existe ainda um desafio do trabalho do profissional de psicologia em uma equipe multidisciplinar. A chegada da Psico-Oncologia no hospital é recente e sua função ainda é frequentemente desconhecida ou distorcida. Mas já existem situações em Hospitais onde o psicólogo não somente é muito valorizado como também é requisitado pelo corpo médico e equipe de saúde, resultando em uma integração do psicólogo a equipe multidisciplinar.

Segundo o instituto nacional do câncer, em 2011 a respeito das possíveis causas, ao tratamento, recuperação e cura, apesar de todo o avanço da medicina, do ensino e pesquisa, sem dúvida, ficam claras as lacunas do conhecimento do que realmente ocorre nos processos oncológicos. Não se sabe quais são todos os fatores desencadeantes do processo cancerígeno e quais os fatores curativos. Os mesmos tratamentos não surtem os mesmos efeitos em pacientes acometidos com os mesmos diagnósticos e prognósticos, atravessando a mesma fase da doença, a priori o que se pode fazer é o investimento no tratamento e o fortalecimento das redes de apoio, bem como a assistência pessoal, psicológica a esse paciente

É essencial compreender e dar suporte a todas as transformações oriundas, decorrentes desde a confirmação do diagnóstico até a fase de recuperação ou fase terminal, bem como ouvir e aprender com o paciente, tendo sempre em mente que, estamos cuidando de um ser humano repleto de experiências, vivências, sonhos, crenças, limitações, dentre outros aspectos e não apenas da enfermidade que ele traz (Miyazaki et al., 2001).

\section{Revisão}

Esta sessão é o trabalho de uma revisão cautelosa da literatura que contribui para um apanhado completo dos trabalhos produzidos com a semelhança do tema abordado neste projeto. Luna (1999) discorre que a revisão de literatura é o resultado de uma melhor localização da questão de pesquisa ou ajustamentos necessários para focar melhor o objeto pesquisado. A revisão de literatura encontra diante das pesquisas que mostram o estado atual da área pesquisada, as lacunas que podem surgir quanto às teorias e formas de pesquisas.

Para a escolha das plataformas a serem usadas, pensou-se na opção através das contribuições que cada base de dados poderia fornecer a pesquisa enquanto coleta de dados. As bases de dados para a pesquisa foram: Coordenação de Aperfeiçoamento de Pessoal de Nível Superior (CAPES) e SciELO (Scientific Electronic Library Online).

1) SciELO - Scientific Electronic Library Online: por apresentar uma grande variedade de trabalhos brasileiros, sendo primordial para a busca intensiva que essa pesquisa se propõe;

2) CAPES - Base de dados Coordenação de Aperfeiçoamento de Pessoal de Nível Superior: a plataforma trata-se de um apanhado geral de dissertações e teses defendidas nos programas de pós-graduação brasileiros que servem como base teórica para a temática proposta;

Foram utilizados como descritores os termos (oncologia + psicologia + paciente com câncer), adotando-se as seguintes direções: 1) Período: considerou-se o período de 2005 a 2020 utilizando apenas uma referência de um ano anterior considerado de grande relevância tendo em vista a importância dos trabalhos mais recentes na área; 2) Idioma: foi feito um levantamento de dados dos trabalhos brasileiros publicados e em seguida considerou-se as citações feitas nos mesmos para assim inserir os trabalhos em outros idiomas; 3 ) Trabalhos que demonstram que suas temáticas estariam alinhadas às temáticas discutidas nesta revisão de literatura (Quadro 1)..

Dessa forma, foram encontrados um total de 1.290 trabalhos no geral, resultados do somatório de trabalhos achados na plataforma CAPES e SciELO, desses, apenas alguns estavam associados a temática voltada a psicologia e o paciente oncológico. Com as demarcações de publicações brasileiras, encontrou-se 860 trabalhos e ao procurar de forma mais intensiva as publicações que surgiram mediante as temáticas mais aproximadas ao tema proposto, encontrou-se 180 artigos em português.

Na base de dados CAPES encontramos um total de 98 artigos com a proximidade da temática destacada e as condições de publicação brasileira que foram as nossas condições para a descrição da pesquisa nesse primeiro momento pesquisando a plataforma SciELO, com a realização do destaque dos termos de pesquisa, 
encontrou-se uma quantidade de 82 trabalhos publicados em português, com a proximidade da temática destacada.

No fim das pesquisas, encontramos um total de 18 artigos que serviram como base de descrição de análise para os resultados e discussões dessa revisão de literatura. Separamos as temáticas por eixos e descrevemos pontualmente cada temática que surgiu como ponto importante de discussão em cada trabalho revisado.

Quadro 1. Principais artigos relacionados ao tema oncologia, psicologia e pacientes com câncer.

\begin{tabular}{|c|c|c|}
\hline Título & Autor & Ano \\
\hline Instituto Nacional do câncer (INCA) & INCA & 2019 \\
\hline Manejo da dor no paciente com doença oncológica: orientações ao médico residente & Oliveira \& Trindade & 2015 \\
\hline Dor no doente com câncer & Teixeira & 2003 \\
\hline Effect of spiritual well-being on end-of-life despair in terminally-ill cancer patients & Mcclain et al. & 2003 \\
\hline Tratamento neurocirúrgico da dor crônica & Hisatugo & 2015 \\
\hline Cognitive behaviour therapy for people with cancer & Moorey \& Greer & 2002 \\
\hline Introdução à psiconcologia & Carvalho & 2017 \\
\hline As estratégias de enfrentamento de pacientes durante o tratamento de radioterapia & Lorencetti \& Simonetti & 2005 \\
\hline Terapia cognitiva dos transtornos de personalidade & Beck et al. & 2017 \\
\hline Kerapia cognitivo-comportamental na prática psiquiátrica & 2004 \\
\hline Cognitive therapy and emotional disorders & Beck & 1979 \\
\hline Tognitive Behavioral therapy for chronic illness and disability & 2005 \\
\hline Tmportância da atuação no tratamento de mulheres com câncer de mama & Venâncio & 2004 \\
\hline Metodologia de avaliação e intervenção na dor no âmbito da psicologia da saúde & Pais Ribeiro & 2015 \\
\hline Tratamento da dor oncológica em cuidados paliativos & Rangel \& Telles & 2012 \\
\hline Diagnósticos de enfermagem com base em sinais e sintomas associados à dor & Pasin et al. & 2011 \\
\hline A visita de familiares em unidades intensivas da ótica da equipe de enfermagem & Predebon et al. & 2011 \\
\hline A atuação do psicólogo com pacientes submetidos a tratamento de câncer & Sabino & 2019 \\
O paciente com câncer: cognições e emoções a partir do diagnóstico & Silva et al. & 2008 \\
\hline
\end{tabular}

\section{Discussão}

\section{O câncer, sua incidência e prevalência}

De acordo com o Instituto Nacional do Câncer (INCA) O câncer se trata de uma neoplasia maligna, caracterizando mais de 100 tipos de doenças, onde ocorre um crescimento descontrolado e nocivo das células, que podem invadir determinado órgão e tecido ou até mesmo se espalhar para diversas regiões do corpo. Essas células se multiplicam muito rápido, são agressivas, e formam diversos tipos de tumores.

Os vários tipos de câncer se diferem um do outro, pelo fato de cada um ser ocasionado por um tipo de célula. A exemplo disso se tem os cânceres de pele, se eles se originam a partir das cartilagens, é chamado condrossarcoma, se ele se origina a partir das mucosas, é chamado carcinoma, originado em células epiteliais, outro fator a diferir um câncer do outro, é a capacidade de rápida multiplicação das células cancerígenas, e a velocidade que as mesmas têm em se espalhar pelo organismo, afetando outros órgãos e tecidos.

Ainda segundo o instituto as causas do câncer, com tantos avanços da medicina, são estudadas, e existem fatores que influenciam o surgimento da doença, esses fatores são denominados causas internas e externas ao organismo, ou ainda podem se correlacionar. Os fatores internos que determinam o surgimento do câncer, na maioria das vezes são determinados geneticamente, e os fatores externos se dão através dos costumes e hábitos de vida do indivíduo.

As causas que levam uma pessoa a desenvolver o câncer, na grande maioria de sua incidência está relacionado aos fatores externos e casuais, com cerca de $90 \%$ dos casos decorrendo desses fatores, pois são os que mais contribuem para o crescimento e multiplicação prejudicial das células, um dos fatores externos e casuais a servir de exemplo, é o cigarro, pois o uso prolongado de suas substâncias pode vir a causar câncer de pulmão.

As células também podem ser modificadas, no processo de envelhecimento do organismo as células se tornando mais suscetíveis a transformações malignas, esse fator também explica a maior incidência de câncer sobre pessoas idosas, pois este grupo teve suas células expostas a fatores cancerígenos externos e casuais por um longo período de tempo (Teixeira, 2003).

A Organização Mundial da Saúde (OMS) enfatiza em suas pesquisas que os cânceres mais comuns são os tumores no estômago e pulmão, tanto em países desenvolvidos, quanto em países emergentes em desenvolvimento. Em relação de incidência do câncer entre mulheres e homens, nos países desenvolvidos, os 
índices de surgimento do câncer em homens e mulheres é similar, já nos países em desenvolvimento, como o Brasil, a incidência é 30\% maior no sexo feminina, entretanto os canceres com os piores índices de sobrevivência são os de estomago e fígado em homens (Oliveira \& Trindade, 2013).

\section{A dor e seus mecanismos neurais}

A dor se define pela lesão de um órgão ou tecido, se manifestando através de reações comportamentais, psicológicas e respostas autônomas, sendo caracterizada como uma experiência de teor complexo. A dor pode ser classificada como aguda, com período de duração rápido ou longo se estendendo desde horas e até meses, sendo sentida pelo indivíduo de maneira constante ou com intervalos, que podem ser agravadas de acordo com a atividade que o indivíduo realiza. Normalmente, a dor está associada a traumas e doenças que geram processos infecciosos e inflamatórios, e sendo resolvidos estes problemas a dor tende a desaparecer (Oliveira \& Trindade, 2013).

Existe ainda dentro da classificação da dor, a dor crônica, que se caracteriza por se estender de maneira constante e incômoda por longos períodos de tempo, que não altera de maneira importante os sinais de vida do paciente, entretanto apresentam sintomas que trazem diversos incômodos, como fadiga, depressão, isolamento social e etc. a dor é uma resposta imunológica do organismo para o indivíduo que serve de alerta para o sistema nervoso central iniciar respostas ao trauma sofrido e minimizar os prejuízos ao corpo (Teixeira, 2003).

Os estudiosos diferem a sensação de dor do acontecimento da nocicepção, que neste caso, se refere aos sintomas da dor que são encaminhados ao sistema nervoso, que ativam os receptores sensoriais, e encaminham ao cérebro a mensagem de que um tecido foi lesionado. Neste sentido, a dor se trata da experiência emocional incomoda que é uma resposta da nocicepção, que se trata da transmissão neurológica da dor ao sistema nervoso central (Pais Ribeiro, 2015).

Dessa forma, a nocicepção é a transmissão neurológica da dor ao cérebro, esse processo se desencadeia logo após o trauma do órgão ou tecido. Onde os neurotransmissores que estão presentes em todo o organismo, desde a pele, até os órgãos e tecidos mais profundos, esses neurotransmissores respondem a traumas nocivos ao organismo. Entretanto, os tecidos e órgãos profundos somente respondem a estímulos extremadamente dolorosos, segundo Rangel \& Telles (2012):

\footnotetext{
“A sensação de dor com origem nos órgãos viscerais é proveniente da forte estimulação de receptores que têm outras funções, tais como, inflamação, estiramento, isquemia, dilatação e espasmos dos órgãos internos que provocam, sem exceção, uma resposta intensa nessas fibras com muitas finalidades e podem causar dores de alta intensidade”.
}

Desse modo, entende-se que existem certos receptores neurais que somente respondem a um tipo de estímulo, e outros como os nociceptores, respondem a três tipos de estímulo, sendo eles térmicos, químicos e mecânicos. Sendo assim, estes receptores transformam o estímulo em informação e essa informação em resposta dolorosa ao sistema nervoso central, e a cada novo estímulo, maior será a resposta dos nociceptores (Rangel \& Telles, 2012).

Em outras palavras, o estímulo repetido, causa uma hiperalgesia, desse modo o paciente irá relatar que a dor cresceu de intensidade em relação ao primeiro estímulo sofrido, os sinais elétricos que o estímulo doloroso provoca, será transmitido ao sistema nervoso central através das fibras aferentes, e a tradução da sensação de dor ocorrerá no córtex cerebral (Hisatugo, 2015).

\section{A dor e seus aspectos emocionais}

Com a dor e seus aspectos neurais, vem também o sofrimento psicológico do paciente, pois a dor causa severos agravos no emocional do paciente, gerando transtornos psicológicos, tais como depressão, ansiedade, apatia, isolamento social etc. Esse comportamento é desencadeado pelo estado emocional já fragilizado com a descoberta da doença, e a dor constante e de graus insuportáveis em muitos casos agrava ainda mais seu estado emocional (Pasin et al., 2015).

O câncer é uma doença, que por si só desencadeia uma série de modificações assustadoras no organismo do paciente, e não é diferente em seu contexto psicológico e emocional, a descoberta da doença promove a um misto de sentimentos e conflitos internos, e muito sofrimento ao paciente, este sofrimento por sua vez, se transforma em diversos transtornos psicológicos, a gravidade e intensidade desses transtornos, depende 
ainda do tipo de câncer, da região afetada, do estágio em que se encontra, se inicial ou se avançado, e do tipo de tratamento que o paciente será submetido (Predebon et al., 2011).

Essa doença, apesar das inúmeras conquistas da medicina em termos de tratamento e sobrevivência dos pacientes, ainda nos dias de hoje, os pacientes encaram o seu diagnóstico como o fim da linha, como a sua sentença de morte. Infelizmente, apesar de os índices serem cada vez mais animadores e favoráveis à cura, ainda assim, a doença é rotulada como terminal, e causadora de óbito (Predebon et al., 2011).

A rotulagem do câncer, promove no indivíduo uma série de reações, e também naqueles que o cerca, a família e os amigos. Passado o estado de choque com a descoberta da doença, muitos pacientes passam a apresentar sintomas como ansiedade, depressão e revolta, e esse aspecto emocional tende a ser negligenciado pelas equipes médicas. $\mathrm{O}$ câncer, é enxergado pelo paciente como uma ameaça ao seu futuro, promovendo a sensação de impotência, medo, levando o paciente a se tornar apático e depressivo (Predebon et al., 2011).

A dor é a consequência mais severa do câncer, e existe o senso comum de que as dores causadas pela doença são incontroláveis. Entretanto, apesar deste senso comum ter fundamento, a dor, quanto sintoma é consequência da doença pode ser controlada, minimizada ou mesmo reduzida por completo, com o uso de algumas medicações analgésicas. A dor, soma-se às incapacidades que o câncer já proporciona ao paciente, causando diversos outros incômodos como o confinamento ao leito, o isolamento social, o afastamento das atividades laborais e das atividades de lazer. A dor, é tida como o fator mais estressante e desumanizante ao paciente, e agravam as consequências emocionais desfavoráveis ao paciente e seus familiares ((Oliveira \& Trindade, 2013).

\section{Implicações emocionais da dor e do câncer na vida do paciente}

Segundo Sabino (2019), o câncer desencadeia reações devastadoras tanto no âmbito orgânico como no emocional, provocando sentimentos, desequilíbrios e conflitos internos, além de causar um sofrimento tão intenso capaz de resultar em desorganização psíquica, consequências estas que, vão depender da localização, do estágio da doença e do tratamento.

Apesar do avanço tecnológico da medicina, o seu diagnóstico ainda é encarado, muitas vezes, como sentença de morte. Desse modo, embora seja comprovado que $50 \%$ dos casos são passíveis de cura ou controle, esta imagem persiste, principalmente pelo rótulo "terminal".

Estes aspectos da doença podem provocar uma série de expectativas e reações no paciente, bem como em seus familiares. Após o choque inicial do diagnóstico, os pacientes costumam apresentar respostas emocionais como ansiedade, raiva e depressão. Assim, torna-se fundamental uma atenção especial para essas reações, visto que, com o advento da tecnologia na medicina, estas necessidades foram ignoradas e negligenciadas pelos médicos (Moorey \& Greer, 2002).

Esta doença, vista pelo indivíduo como uma ameaça do destino, desencadeia uma série de sentimentos como impotência, desesperança, temor e apreensão, levando o diagnóstico a ser, frequentemente, acompanhado de depressão, consequência ocorrida pelo fato do paciente não conseguir aceitar sua doença (Carvalho, 2017).

Conforme afirma Venâncio (2004), o diagnóstico de câncer é vivido como um momento de angústia e ansiedade, pelo motivo da doença ser rotulada como dolorosa e mortal, consequentemente, desencadeando preocupações em relação à morte. Além do momento do diagnóstico, ao longo do tratamento, o paciente vivencia perdas e diversos sintomas que, além de acarretar prejuízos ao organismo, coloca-o diante da incerteza em relação ao futuro, aumentando assim sua ansiedade.

Segundo pesquisa de Silva et al. (2008) uma outra possível forma de reação ao diagnóstico é o suicídio. Esta vulnerabilidade é demonstrada amplamente na literatura oncológica como, por exemplo, indicaram ser o câncer um fator de risco para o suicídio, logo após o diagnóstico. Já em outros a depressão aliada a outros fatores, tais como o estado civil e o nível de sofrimento físico, estariam relacionados como a ideação suicida neste tipo de enfermidade.

Entretanto, os pacientes encontram estratégias para o enfrentamento do diagnóstico através da espiritualidade. Autores como McClain et al. (2003) investigaram o efeito da espiritualidade em pacientes terminais com câncer numa amostra de 160 pacientes de um hospital. A pesquisa indicou correlações negativas entre bem-estar espiritual e desesperança $(r=-0,68)$ e ideação suicida $(r=-0,41)$, sugerindo que $o$ bem estar espiritual é um fator de proteção contra o desespero da morte.

Lorencetti \& Simonetti (2005) desenvolveram um trabalho com pacientes oncológicos, acerca das estratégias de enfrentamento utilizadas diante da doença e do tratamento, verificando que os pacientes entrevistados criam meios para enfrentá-los, como forma de amenizar o sofrimento e lidar com a situação. 
A religiosidade então, é usada, de acordo com Linard et al. (2002), como suporte para se conviver com a doença, podendo representar uma importante fonte de suporte e conforto para muitas pessoas, durante um período de sofrimento, proporcionando um maior equilíbrio diante das adversidades da doença.

Diante de todo o desgaste físico e emocional vivenciados pelo paciente perante o diagnóstico de uma doença maligna, que o coloca em iminência de morte e que o faz submeter-se a procedimentos terapêuticos invasivos e, muitas vezes, mutilantes, o indivíduo é tomado por sentimentos de raiva, medo, angústia, pena de si mesmo, além da sensação de ter perdido o controle em relação a sua vida

Nesta perspectiva, o diagnóstico da doença acaba por provocar uma série de reações emocionais no paciente, que apresentam relação com as cognições ativadas ao receber o diagnóstico. Assim, considera-se pertinente o modelo cognitivo desenvolvido por Aaron Beck, em que se propõe haver uma inter-relação recíproca entre pensamento, emoção e comportamento, pois a interpretação de um evento pode ativar cognições e tais cognições podem influenciar emoções e comportamento (Beck et al., 2017).

A atividade cognitiva, ativada com o diagnóstico de uma doença crônica como o câncer, pode influenciar o comportamento e as emoções do paciente, alterando a forma como ele se sente, e podendo resultar em transtornos psicológicos decorrentes de um modo distorcido de se perceber os acontecimentos, denominado distorções cognitivas.

Segundo Knapp (2004), às distorções cognitivas normalmente podem se apresentar, numa mesma situação, concomitantemente, de diversas maneiras: por catastrofização (pensar sempre que o pior vai acontecer), por abstração seletiva (focar a atenção em um aspecto negativo da situação), por adivinhação (antecipar problemas, ter expectativas negativas em relação a fatos, que talvez nem venham a existir), por personalização (assumir a culpa por acontecimentos negativos), entre outras.

Os pensamentos que, às vezes, vêm distorcidos ou não, ocorrem em três níveis: o primeiro denominado pensamento automático, o segundo nomeado crenças intermediárias ou subjacente e o terceiro nível definido como crença central, que dá origem a crença intermediária, desencadeadora de pensamentos automáticos, quando o indivíduo se coloca diante de algumas situações (Falcone, 2001).

Estes pensamentos automáticos, que correspondem àqueles pensamentos espontâneos, fluem na mente, independente do raciocínio, sob a forma de pensamento ou de imagem, são breves e coexistem com um fluxo manifesto de pensamentos, sem serem embasados por uma reflexão (Beck, 1979).

Segundo Knapp (2004), estas formas de pensamentos ocorrem em todas as pessoas diariamente, de forma que não são percebidos por acontecerem de forma rápida, involuntária. Eles podem ser ativados através de eventos internos ou externos, entretanto, quando são distorcidos ou disfuncionais, contribuem para psicopatologia por influenciarem tanto as emoções como os comportamentos dos indivíduos.

O nível de pensamento, aqui descrito, é evocado pelas crenças intermediárias, também chamadas de crenças condicionais, e corresponde ao segundo nível do pensamento que ocorre sob forma de crenças ou regras. Essas crenças refletem idéias mais enraizadas e mais difíceis de serem modificadas do que os pensamentos automáticos, porém mais maleáveis do que as crenças centrais Knapp (2004).

De acordo com (Falcone, 2001) e Knapp (2004), as crenças intermediárias pressupõem que, se algumas regras ou atitudes forem cumpridas, o indivíduo permanecerá estável, caso contrário, ele estará vulnerável. Apesar do indivíduo construir essa crença como uma forma para reduzir o sofrimento provocado pela crença central, ele, com isso, apenas contribui para reforçar ou confirmar ainda mais suas crenças centrais.

Conforme os referidos autores, as crenças centrais correspondem ao nível mais profundo do pensamento constituído por idéias e conceitos mais enraizados acerca de si, dos outros e do mundo, consideradas como verdades absolutas e imutáveis, sendo também consideradas incondicionais, pois, para que ocorra, independe da situação vivenciada pelo indivíduo. A construção dessas crenças se dá a partir das primeiras experiências e vão se fortalecendo ao longo da vida, tornando-se cada vez mais convincentes na vida adulta, mesmo que ocorram algumas experiências que não as confirmem.

Há uma interligação entre os níveis de cognições mencionadas e as crenças construídas ao longo das experiências de vida. Estas vão contribuir diretamente na formação da crença central do indivíduo e dão origem às crenças intermediárias que, por fim, deixam a pessoa mais propensa a experimentar pensamentos automáticos disfuncionais.

Segundo Taylor (2005), os pensamentos automáticos mais comuns em um paciente diagnosticado com uma doença crônica podem ser divididos em três eixos: (1) sofrimento físico: Eu serei capaz de suportar este sofrimento? (2) qualidade de vida: eu serei capaz de comer o que eu gosto novamente? Como isto afetará a minha vida sexual? e (3) mortalidade: eu vou morrer?

No que concerne especificamente ao câncer, a pesquisa de Silva et al. (2008) cita a definição do autor Barraclough et al., (2019) que exemplifica que uma mulher com câncer no seio pode acreditar que "nenhum 
homem deseja uma mulher com apenas um seio". Já um homem que perdeu seu pai com câncer há anos, quando os recursos da medicina não eram tão desenvolvidos, pode acreditar que "a morte com câncer é agonizante".

Assim, autores como Moorey \& Greer (2002) advogam que a terapia cognitiva poderia ajudar o paciente a adaptar o tratamento a suas vidas bem como adaptar as visões de si próprios a esta nova situação. Já Taylor (2005) argumenta algumas razões para utilizar a terapia cognitiva comportamental com pacientes crônicos, tais como: facilitar a aderência ao tratamento; oferecer suporte emocional frente ao diagnóstico, prevenir comportamentos de risco à saúde, dentre outros.

Tendo em vista estas considerações, percebe-se que as cognições possuem um papel importante tanto na melhora do estado emocional quanto na qualidade de vida. Assim convém, no presente estudo, ter como objetivo investigar as cognições ativadas e os sentimentos despertados nos pacientes, no momento do diagnóstico.

\section{Considerações finais}

Como citado no início da pesquisa as reflexões dos pacientes a partir da sua relação com a doença desenvolvem diálogos de imensa importância para a área da psico-oncologia, impactando as práticas do profissional diante de uma demanda tão rica de detalhes e subjetividades. A pauta principal do artigo foi apresentar de forma acolhedora as emoções dos pacientes que lidam diariamente com as pautas oncológicas e os impactos emocionais em diferentes momentos da enfermidade.

Diante das buscas realizadas foi possível observar a recente inserção da psico oncologia nos hospitais assim como o reconhecimento gradual das equipes médicas com relação a importância desse profissional , principalmente reconhecendo que a alta realização de exames que por vezes podem ser invasivos causam um estresse extremo nos pacientes e em seus familiares e que o próprio diagnóstico já podem desencadear alguns transtornos como ansiedade depressão, esse comportamento se desenvolve no avançar da doença provocando muitos conflitos internos.

Sendo assim a necessidade de ouvir os relatos e reflexões dos próprios pacientes têm papel fundamental no desenvolvimento de práticas psicológicas que se adequem a essas demandas, as percepções do paciente variam a partir de suas crenças vão desde uma ameaça ao seu futuro ou uma provação divina ou até o simples sentimento de frustração oriundo dos mais variados pensamentos automáticos

Portanto, esta pesquisa contribui para o desenvolvimento de práticas assertivas para esses pacientes, com uma visão ampliada do sujeito e sua demanda podendo servir como base de projetos futuros para práticas mais assertivas acerca do cuidado voltado a pacientes oncológicos.

\section{Referências}

Amorim, A. M. 1999. A enfermagem e a psiconeuroimunologia no câncer de mama. Rio de Janeiro: Escola de Enfermagem Anna Nery, 142p.

Beck, A. T, Davis, D. D., \& Freeman, A. 2017. Terapia cognitiva dos transtornos de personalidade. $3^{\text {a }}$ ed. Porto Alegre: Artmed.

Beck, A. T. 1979. Cognitive therapy and emotional disorders. New York: International University Press.

Carvalho, M. M. M. J. 2000. Introdução a psiconcologia. In Introdução a Psiconcologia. [S. l.], Livro pleno.

Falcone, E. (2001). Psicoterapia comportamental e cognitiva: Transtornos psiquiátricos. Campinas: Editora Livro Pleno.

Gimenes, M, G. 2007. A mulher e o câncer. São Paulo: Editorial Psy, 325p.

Gimenes, M. G. 2010. Um pouco da história da psico-oncologia no Brasil. In: Angerami-Camon, W. (Org.), Psicologia da saúde. São Paulo: Pioneira.

Hisatugo, M. K. I. 2015. Tratamento neurocirúrgico da dor crônica. In: Sakata, R. K., \& Issy, A. M. Dor. Manole: São Paulo, 251-259.

Instituto Nacional de Câncer [INCA]. 2020. O QUE é câncer?. Disponível em: https://www.inca.gov.br/o-quee-cancer. Acesso em: 20 jul. 2020.

Knapp, P. 2004. Terapia cognitivo-comportamental na prática psiquiátrica. Porto Alegre: Artmed.

Linard, A. G., Dantas e Silva, F. A., \& Silva, R. M. 2002. Mulheres submetidas ao tratamento para câncer de colo uterino: percepção de como enfrentam a realidade. Revista brasileira de cancerologia, 48(4), 493-498. 
Lorencetti, A., \& Simonetti, J. P. 2005. As estratégias de enfrentamento de pacientes durante o tratamento de radioterapia. Revista Latino-Americana de Enfermagem, 13(6), 944-950.

Luna, S.V. 1999. Planejamento de pesquisa: uma introdução. São Paulo: Educ, 107p.

McClain, C. S., Rosenfeld, B., \& Breitbart, W. 2003. Effect of spiritual well-being on end-of-life despair in terminally-ill cancer patients. The Lancet, 361(9369), 1603-1607.

Miyazaki, M. C. O. S., Domingos, N. A. M., Caballo, V. E., \& Valerio, N. I. 2001. Psicologia da saúde: intervenções em hospitais públicos. In: Range, B. (Org.). Psicoterapia cognitivo-comportamental: um diálogo com a psiquiatria. $2^{\mathrm{a}}$ ed. Porto Alegre, RS: Artmed, 568-580.

Moorey, S., \& Greer, S. 2002. Cognitive behaviour therapy for people with cancer. Oxford: Oxford University Press.

Oliveira, P. M., \& Trindade, L. C. T. 2013. Manejo da dor no paciente com doença oncológica: orientações ao médico residente. Revista do Médico Residente, 15(4), 298-304.

Pais Ribeiro, J. 2015. Metodologia de avaliação e intervenção na dor no âmbito da psicologia da saúde. In: N. Barata (Cord.). A dor: Uma visão multidisciplinar. Lisboa, PT: Coisas de Ler Edições, Lda, 135-150.

Pasin, S., Ferreira, A. M., Predebon, C. M., \& Silva, E. R. R. 2011. Diagnósticos de enfermagem com base em sinais e sintomas associados à dor. In: Silva, E. R. R., \& Lucena, A. F. Diagnósticos de enfermagem com base em sinais e sintomas. Porto Alegre: Artmed, 283-294.

Predebon, G. R., Beuter, M., Flores, R. G., Girardon-Perlini, N. M. O., Brondani, C. M., \& Santos, N. O. 2011. A visita de familiares em unidades intensivas da ótica da equipe de enfermagem, 10(4), 705-712.

Rangel, O., \& Telles, C. 2012. Tratamento da dor oncológica em cuidados paliativos. Revista do Hospital Universitário Pedro Ernesto, 11(2), 32-37.

Sabino, C. J. 2019. A atuação do psicólogo com pacientes submetidos a tratamento de câncer. Trabalho de Conclusão de Curso (Graduação) - Faculdade de Leão Sampaio, Curso de Graduação em Psicologia, Juazeiro do Norte, $17 \mathrm{p}$.

Silva, S. S, Aquino, T. A. A., \& Santos, R. M. 2008. O paciente com câncer: cognições e emoções a partir do diagnóstico. Revista Brasileira de Terapias Cognitivas, PEPSIC, 4(2).

Taylor, R. R. 2005. Cognitive behavioral therapy for chronic illness and disability. Chicago: University Illinois Press.

Teixeira, E., \& Pires, Eliana. 2010. Psico-oncologia: proposta de trabalho de apoio psicossocial aos pacientes com câncer. Revista Saúde, 4(1), 2010.

Teixeira, M. J. 2003. Dor no doente com câncer. In: Teixeira, M. J., Braum Filho, J. L., Márquez, J. O., \& Yeng, L. T. Dor: contexto interdisciplinar. Curitiba: Maio, 329p.

Venâncio, J. L. 2004. Importância da atuação no tratamento de mulheres com câncer de mama. Revista Brasileira de Cancerologia, 50(1), 55-63.

\section{Minicurrículo}

Milena Freitas Da Silva. Acadêmica de Psicologia, atuando com ênfase em saúde, tendo como principais áreas de interesse a Psico-oncologia e as neurociências.

Julianne Milenna Padilha Rolim. Psicóloga Especialista em Psicologia Organizacional e Psicologia do Trânsito Mestra em Gestão Empresarial Docente da Autarquia de Ensino Superior - AESA/ESSA e Faculdade Integrada - CETE/FIC

Como citar: Silva, M.F., \& Rolim, J.M.P. 2021. O paciente com câncer, cognições e emoções oriundas da dor: uma revisão literária a partir de uma perspectiva psicológica. Pubsaúde, 6, a173. DOI: https://dx.doi.org/10.31533/pubsaude6.a173

Recebido: 29 abr. 2021.

Revisado e aceito: 19 mai. 2021.

Conflito de interesse: os autores declaram, em relação aos produtos e companhias descritos nesse artigo, não ter interesses associativos, comerciais, de propriedade ou financeiros que representem conflito de interesse.

Licenciamento: Este artigo é publicado na modalidade Acesso Aberto sob a licença Creative Commons Atribuição 4.0 (CC-BY 4.0). 